\title{
PEMELIHARAAN JALAN DAN BANGUNAN PELENGKAP JALAN PADA DAERAH TRANSMIGRASI
}

(Kumai Seberang Kabupaten Kotawaringin Barat Provinsi Kalimantan Tengah)

\section{MAINTENANCE OF ROADS AND SUPPLEMENTARY ROADS IN THE TRANSMIGRATION AREA}

\author{
Pingkan Nuryanti ${ }^{1}$, Novita Sari ${ }^{2}$ \\ ${ }^{1}$ Institut Pertanian Bogor, Kampus Dramaga \\ ${ }^{2}$ Politeknik Transportasi Darat-STTD, Bekasi \\ *Email: pingkannuryanti@apps.ipb.ac.id
}

\begin{abstract}
Central Kalimantan is one of the largest transmigration recipient areas in Indonesia, one of which is the Kumai Seberang area, West Kotawaringin Regency. The limited budget for the construction of transmigration settlement infrastructure has an impact on the condition of transportation infrastructure in the area. Meanwhile, the existence of this transportation infrastructure is the lifeblood of the economic growth and development of a region. In this area, many roads and complementary road buildings were found that were damaged. This can be caused by the planning of the road body that does not meet the requirements or the quality of the road pavement which is still below the standard. Based on these problems, it is necessary to evaluate the field to find out the problems that exist in the field. In addition, it provides recommendations to the community to deal with problems in the field independently. The method used in this research is field observation and interviews with the community. The results of observation obtained data regarding the condition of roads, bridges, and road complementary buildings that are still in good condition only need maintenance so that they are used more optimally, while in the drainage channel there is erosion on the cliffs and there is a lot of sediment deposition resulting in silting. To overcome the problems that exist in the field, the community can use easily available local natural resources such as wood. The community also needs to learn about road maintenance processes and techniques in solving problems, especially in the road sector. The government must also provide guidance and assistance in the form of funds to the Kumai Seberang community.
\end{abstract}

Keywords: Road Infrastructure, Bridge, drainage channel, transmigration area

\begin{abstract}
Abstrak
Kalimantan Tengah merupakan salah satu daerah penerima transmigrasi yang cukup besar di Indonesia, dimana salah satunya ada daerah Kumai Seberang Kabupaten Kotawaringin Barat. Keterbatasan anggaran untuk pembangunan prasarana permukiman transmigrasi memberi dampak pada kondisi prasarana transportasi pada wilayah tersebut. Sementara itu keberadaan prasarana transporasi ini menjadi urat nadi dalam pertumbuhan ekonomi dan perkembangan suatu wilayah. Pada wilayah ini banyak ditemukan jalan dan bangunan pelengkap jalan yang mengalami kerusakan. Hal tersebut bisa disebabkan oleh perencanaan badan jalan yang kurang memenuhi syarat maupun kualitas perkerasan jalan yang masih dibawah standar. Berdasarkan permasalahan tersebut maka perlu dilakukan evaluasi ke lapangan untuk mengetahui permasalahan yang ada dilapangan. Selain itu memberikan rekomendasi kepada masyarakat untuk menangani masalah di lapangan tersebut secara mandiri. Metode yang digunakan dalam penelitian ini adalah metode observasi dan wawancara kepada pihak masyarakat. Dari hasil observasi lapangan diperoleh data mengenai kondisi jalan, jembatan dan bangunan pelengkap jalan yang masih dalam kondisi yang baik hanya perlu perawatan agar penggunaan lebih optimal, sedangkan pada saluran drainase terdapat erosi pada tebing dan terdapat banyak endapan sedimen sehingga terjadi pendangkalan. Untuk mengatasi permasalahan yang ada di lapangan tersebut masyarakat dapat menggunakan sumber daya alam lokal yang mudah didapat seperti kayu. Masyarakat juga perlu belajar mengenai proses dan teknik pemeliharaan jalan dalam penyelesaian masalah khususnya dalam bidang jalan. Pemerintah juga harus memberikan pembinaan serta bantuan berupa dana pada masyarakat Kumai Seberang.
\end{abstract}

Kata kunci: Infrastruktur Jalan, jembatan, saluran drainase, area transmigrasi 


\section{A. PENDAHULUAN}

Jalan merupakan prasarana transportasi dimana bagian dari jalan meliputi bagungan pelengkap dan perlengkapannya (Undang-Undang Republik Indonesia Nomor 38 Tahun 2004)). Jalan memiliki peranan penting dalam perkembangan suatu wilayah, dimana aktivitas masyarakat ekonomi masyarakat berdampak pada pekembangan perekonomian suatu wilayah (Warsilan dan Noor A, 2015). Kalimantan Tengah merupakan salah satu daerah penerima transmigrasi yang cukup besar di Indonesia salah satunya adalah daerah Kumai Seberang kabupaten Waingin Barat. Tujuan pembangunan transmigrasi di daerah ini adalah untuk menunjang perkembangan daerah khususnya melalui penyediaan sumber daya manusia yang tangguh dan trampil yang dikaitkan dengan usaha pembukaan atau pengembangan daerah produksi baru, peningkatan kualitas pemukiman transmigrasi yang telah ada, pengembangan pola-pola usaha melalui perencanaan terpadu dengan sektor lain. Keterbatasan anggaran pemerintah dalam pemeliharaan ruas jalan penghubung daerah transmigrasi mengakibatkan lambatnya penanganan masalah.

Kerusakan badan jalan beserta bangunan pelengkapnya pada dasarnya dapat ditangani oleh masyarakat yang bermukim di sekitar ruas jalan tersebut. Sehingga keberlangsungan sector perekonomian dan sector-sektor lain tidak terhambat oleh kerusakan pada badan jalan dan bangunan pelengkapnya. Untuk itu dibutuhkan métode pemeliharaan jalan yang sederhana dan mudah dipahami oleh masyarakat agar kepedulian masyarakat terhadap prasarana lingkungan dan kawasan menjadi semakin meningkat. Metode ini di rancang untuk tidak membebani masyarakat sekitar secara financial sehingga metode pemeliharaan jalan dan banguan pelengkapnya di usulkan berasal dari sumber daya alam sekitar.

Tujuan penelitian ini adalah mengevaluasi permasalahan yang ada dilapangan. Selain itu memberikan rekomendasi kepada masyarakat untuk menangani masalah di lapangan tersebut secara mandiri. Selain itu untuk membantu pemerintah dalam pembinaan masyarakat agar peduli dalam pengelolaan dan pemeliharaan sarana dan prasarana kawasan mereka.

\section{B. TINJAUAN PUSTAKA Jalan Desa}

Jalan desa adalah jalan yang dapat dikategorikan sebagai jalan dengan fungsi lokal di daerah pedesaan. Berdasarkan Undang-Undang No.38 tahun 2004 jalan desa merupakan jalan umum yang menghubungkan kawasan dan/atau antarpermukiman di dalam desa, serta jalan lingkungan. Artinya sebagai penghubung antar desa atau ke lokasi pemasaran, sebagai penghubung hunian/perumahan, juga sebagai penghubung desa ke pusat kegiatan yang lebih tinggi tingkatnya (kecamatan). Pembuatan jalan desa disarankan peningkatan jalan lama yang sudah ada. Hal ini untuk menghindari banyaknya volume pekerjaan dan kesulitan pembebasan tanah. Akan tetapi kadang-kadang tidak dapat dihindarkan untuk membuat jalan baru atau peningkatan jalan setapak. Pembangunan jalan di daerah pedesaan, selain perlu memperhatikan aspek teknis konstruksi jalan, juga perlu mempertimbangkan aspek konservasi tanah mengingat kondisi wilayah dengan topografi yang sering berbukit dan dengan tanah yang peka erosi. Pengamatan di lapangan menunjukkan bahwa tidak sedikit erosi tanah yang berasal dari jalan, khususnya berupa longsoran dari tampingan dan tebing jalan.

Menurut Peraturan Menteri Pekerjaan Umum Nomor : 13 /PRT/M/2011, Pemeliharaan jalan adalah kegiatan penanganan jalan, berupa pencegahan, perawatan dan perbaikan yang diperlukan untuk mempertahankan kondisi jalan agar tetap berfungsi secara optimal melayani lalu lintas sehingga umur rencana yang ditetapkan dapat tercapai. 


\section{Bangunan Pelengkap Jalan}

Bangunan Pelengkap Jalan merupakan bangunan untuk mendukung fungsi dan keamanan konstruksi. Jembatan, tembok penahan tanah, dan saluran drainase yang dibangun sesuai dengan persyaratan teknis termasuk bangunan pelengkap jalan (Peraturan Menteri Pekerjaan Umum Republik Indonesia Nomor 13/PRT/M/2011).

Bangunan pelengkap Jalan berfungsi sebagai: jalur lalu lintas, pendukung konstruksi jalan dan fasilitas lalu litas serta pendukung pengguna jalan.

Dinding penahan tanah (Wibisono dkk, 2018) merupakan konstruksi yang dibangun untuk melindungi tebing dari kerusakan atau bahaya erosi. Cara yang digunakan untuk perlindungan tebing antara lain: Saluran diversi (pembagi), teras bangku, talud batu kosong, talud pasangan batu, bronjong, dan perlakuan vegetatif.

Saluran Drainase mencegah genangan (Auzan AN dkk, 2017) dengan mengalirkan air aliran permukaan, sehingga kekuatan air mengalir tidak merusak tanah, tanaman, dan/atau bangunan konservasi lainnya. Pada areal rawan longsor, pembuatan saluran drainase ditujukan untuk mengurangi laju infiltrasi dan perkolasi, sehingga tanah tidak terlalu jenuh air, sebagai faktor utama pemicu terjadinya longsor. Bentuk saluran drainase, khususnya di lahan usaha tani dapat dibedakan menjadi: saluran pengelak, saluran teras, saluran pembuangan air (termasuk bangunan terjunan) Pintu air (gates) digunakan untuk mengatur, membuka dan menutup aliran air di saluran baik yang terbuka maupun tertutup. Bagian yang penting dari pintu air adalah:

a. Daun pintu (gate leaf)

Adalah bagian dari pintu air yang menahan tekanan air dan dapat digerakkan untuk membuka , mengatur dan menutup aliran air.

b. Rangka pengatur arah gerakan (guide frame)

Adalah alur dari baja atau besi yang dipasang masuk ke dalam beton yang digunakan untuk menjaga agar gerakan dari daun pintu sesuai dengan yang direncanakan.

c. Angker (anchorage)

Adalah baja atau besi yang ditanam di dalam beton dan digunakan untuk menahan rangka pengatur arah gerakan agar dapat memindahkan muatan dari pintu air ke dalam konstruksi beton.

d. Hoist

Alat untuk menggerakkan daun pintu air agar dapat dibuka dan ditutup dengan mudah.

Jembatan merupakan suatu konstruksi atau struktur bangunan yang menghubungkan rute/lintasan transportasi yang terpisah baik oleh sungai, rawa, danau, selat, saluran, jalan raya, jalan kereta api, atau perlintasan lainnya. Menurut Bambang dan Muntohar (2007), bahwa jembatan kayu merupakan jembatan dengan material yang dapat diperbaharui (renewable). Kayu adalah sumber daya alam yang pemanfaatannya akhir-akhir ini banyak pada bidang industri kayu lapis, furnitur. Dapat dikatakan sangat sedikit pemakaiannya dalam bidang jembatan secara langsung sebagai konstruksi utama. Paling tidak penggunaan kayu sebagai bekisting untuk jembatan.

Ketersediaan bahan kayu akan sangat terkait erat dengan potensi hutan disuatu wilayah. Seperti halnya Indonesia yang memiliki cukup luas hutan tropis tentunya akan sangat menunjang dalam proses konstruksi jembatan-jembatan sederhana yang terbuat dari kayu.

Kayu mempunyai beberapa keuntungan baik secara langsung maupun tidak langsung yang antara lain seperti berikut ini (Barker \& Pucket, 1997). Sifat-Sifat Jembatan Kayu:

a. Kayu relatif ringan, biaya transportasi dan konstruksi relatif murah, dan dapat dikerjakan dengan alat yang lebih sederhana.

b. Pekerjaan-pekerjaan detail dapat dikerjakan tanpa memerlukan peralatan khusus dan tenaga ahli yang tinggi. Sebagai contohnya pada sambungan konstruksi jembatan baja memerlukan peralatan dan ketrampilan tenaga kerja tersendiri, sedangkan pada konstruksi kayu dapat menggunakan bor tangan.

c. Jembatan kayu lebih suka menggunakan dek dari kayu, yang mana menguntungkan untuk lokasi yang terpencil dan jauh dari lokasi pembuatan beton siap pakai (ready mix concrete). Dek kayu dapat dipasang tanpa bekisting dan tulangan, sehingga menghemat biaya. 
d. Kayu tidak mudah dipengaruhi oleh korosi seperti pada baja atau beton.

e. Kayu merupakan bahan yang sangat estetik, bila didesain dengan benar dan dipadukan dengan lingkungan sekitar.

\section{METODOLOGI PENELITIAN}

Metode yang digunakan dalam penelitian ini adalah observasi dan wawancara. Observasi dilakukan untuk mengetahui kondisi umum masyarakat serta untuk mengetahui kondisi sarana dan prasarana yang ada di daerah Kumai Seberang. Sedangkan kegiatan wawancara dilakukan pada saat dilakukan sosialisasi kepada masyarakat mengenai mengenai teknis-teknis pemeliharaan jalan transmigrasi. Kerangka pikir penelitian dapat dilihat pada "Gambar. 1".

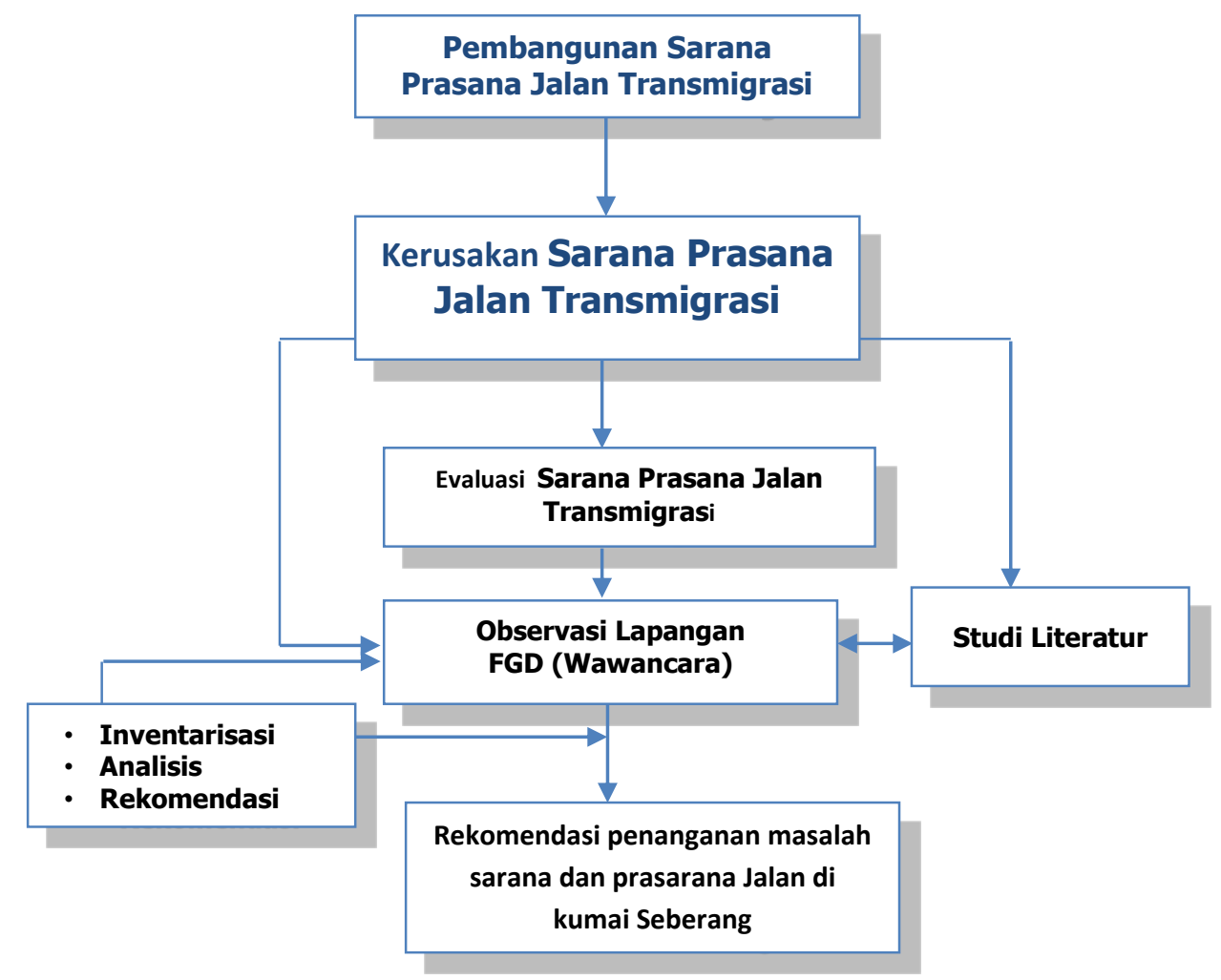

Gambar. 1 Kerangka Pikir Penelitian

\section{HASIL DAN PEMBAHASAN}

\section{Kondisi Umum}

UPT Kumai Seberang terletak di Kecamatan Kumai Seberang Kabupaten Kotawaringin Barat Provinsi Kalimantan Tengah (www.depnakertrans.go.id, 2011). Secara Geografis Lokasi terletak pada koordinat : $111^{0} 43^{00} 22,112^{0} 45^{00} 26$, BT dan $02^{0} 45^{00} 55,02^{0} 47^{00} 27$ LS. Luas Areal pencadangan 550 Ha dengan daya tamping $275 \mathrm{KK}$ calon transmigrant. Mayoritas mata pencaharian penduduk adalah berkebun, bertani dan berdagang.

Tabel 1 Perbatasan Wilayah

\begin{tabular}{c|c}
\hline Bagian & Perbatasan \\
\hline Utara & Lingkar Kumai Seberang, Kel Kumai Hilir \\
\hline Selatan & Desa Sekotet \\
\hline Barat & Kel Kumai Hilir \\
\hline Timur & Desa Sei Bedan dan Sekonyes \\
\hline
\end{tabular}


Curah hujan terdiri dari dua jenis, yaitu bulan basah (Juli sd Agustus) dan bulan kering (Mei sd Oktober). Sedangkan ketersediaan air bersih yang digunakan penduduk bersumber dari air sumur gali. Fasilitas yang digunakan pada daerah Kumai Seberang pada umumnya menggunakan kayu, seperti bangunan rumah dan jembatan.

Tabel 2 Aksebilitas

\begin{tabular}{c|c|c}
\hline Dari - Ke & Jarak Tempuh & Jenis Kendaraan \\
\hline Provinsi - Kabupaten & $3 \mathrm{~km}$ & Jalan darat, roda 4 \\
\hline Kabupaten - Kecamatan & $14 \mathrm{~km}$ & Jalan darat, roda 4 \\
\hline Kecamatan - Lokasi & $5 \mathrm{~km}$ & Jalan darat, klotok \\
\hline
\end{tabular}

Tabel 3 Jenis tanaman dengan kesesuaian lahan

\begin{tabular}{c|c}
\hline Jenis Tanaman & Tanaman \\
\hline Pangan & Padi sawah \\
\hline Palawija & Jagung, sayuran \\
\hline Perkebunan & - \\
\hline Komoditas Unggulan & Padi \\
\hline
\end{tabular}

Fasilitas gedung sekolah yang terdapat di sekitar lokasi hanya Sekolah Dasar, sedangkan untuk tingkat SLTP dan SLTA tersedia di ibukota kecamatan atau kabupaten. Tabel 4 menjabarkan sarana Pendidikan yang ada di lokasi.

Tabel 4 Sarana Pendidikan

\begin{tabular}{c|c}
\hline Sarana Pendidikan & Jumlah \\
\hline SD & 1 Unit \\
\hline SLTP & 2 Unit \\
\hline SLTA & 1 Unit di Ibukota Kecamatan \\
\hline
\end{tabular}

Tabel 5 Sarana Kesehatan

\begin{tabular}{c|c}
\hline Sarana Kesehatan & Jumlah \\
\hline Puskesmas & - Unit \\
\hline Puskesmas Pembantu & 1 Unit \\
\hline Posyandu & - Unit \\
\hline
\end{tabular}

Tabel 6 Sarana Ibadah

\begin{tabular}{c|c}
\hline Sarana Ibadah & Jumlah \\
\hline Masjid & 1 Unit \\
\hline Mushola & - Unit \\
\hline Gereja & - Unit \\
\hline
\end{tabular}

Tabel 7 Sarana dan Fasilitas Umum Lainnya

\begin{tabular}{c|c}
\hline Sarana & Jumlah \\
\hline Kantor KUPT & 1 Unit \\
\hline Balai Desa/Adat & 1 Unit \\
\hline Pasar/Warung & - Unit \\
\hline Gudang & 1 Unit \\
\hline Koperasi & - Unit \\
\hline Telekomunikasi & - Unit \\
\hline Tambahan Kapal & - Unit \\
\hline Rumah Petugas & 1 Unit \\
\hline
\end{tabular}


Tabel 8 Pembagian Lahan

\begin{tabular}{c|c}
\hline Jenis Lahan & Luas \\
\hline Lahan Pekarangan & $0,25 \mathrm{Ha} / \mathrm{KK}$ \\
\hline Lahan Usaha I & $0,75 \mathrm{Ha} / \mathrm{KK}$ \\
\hline Lahan Usaha II & $1,00 \mathrm{Ha} / \mathrm{KK}$ \\
\hline
\end{tabular}

\section{ANALISIS}

Setelah dilakukan kegiatan observasi dan menemukan permasalahan yang ada dilapangan selanjutnya dilakukan kegiatan sosialisasi dan pemberian materi mengenai teknis-teknis pemeliharaan jalan transmigrasi dapat dilihat pada "Gambar. 2" dalam sosialisasi tersebut berlangsung kegiatan wawancara yang berisi tanya jawab dengan masyarakat mengenai permasalahan apa saja yang ada dilapangan.
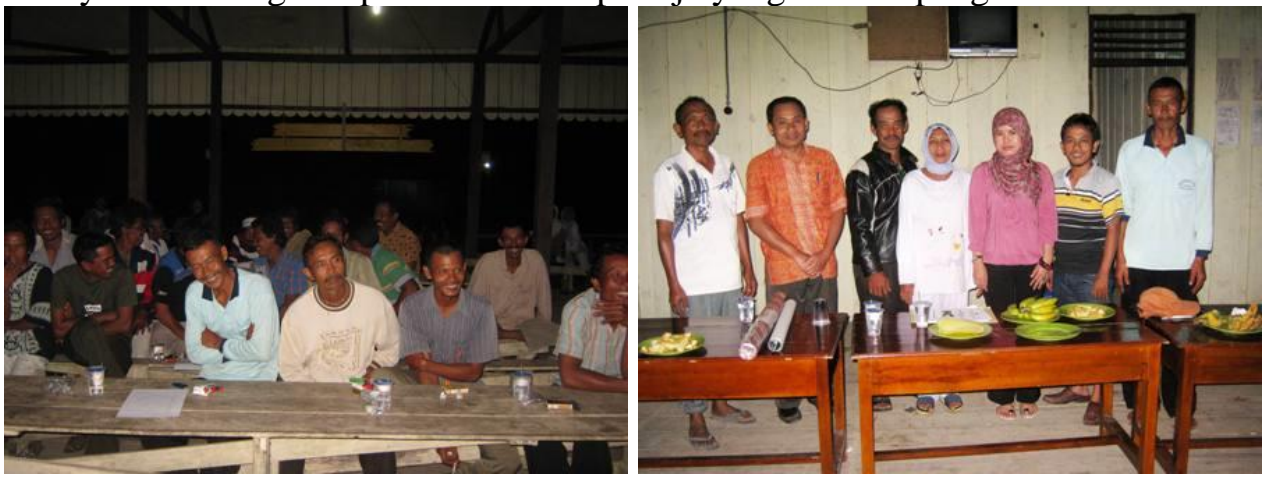

Gambar. 2 Sosialisasi dan wawancara

Setelah kegiatan sosialisasi dan wawancara dilakukan dilakukan observasi ke lapangan secara bersama-sama dengan masyarakat, sekaligus memberikan penjelasan kepada masyarakat cara penanganan sederhana di lapangan. Hal ini dapat dilihat pada "Gambar. 3".

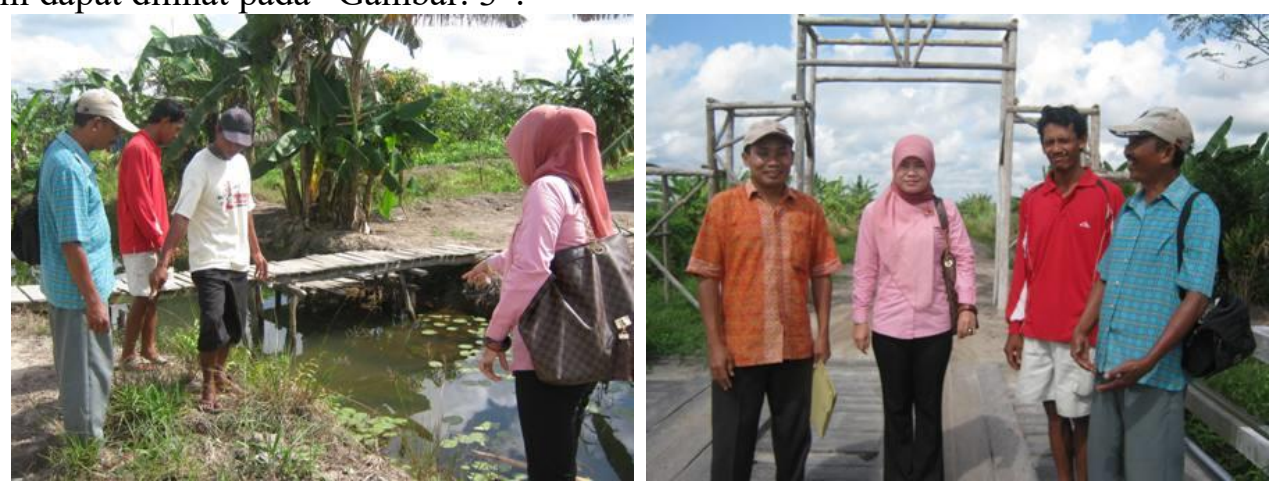

Gambar. 3 Observasi Lapangan

Kondisi sarana dan prasarana di Kumai seberang dijabarkan seperti berikut ini:

a. Jalan

Jalan transmigrasi sudah diberi lapisan sirtu (pasir batuan), akan tetapi belum secara menyeluruh hanya sepanjang $2 \mathrm{kM}$, masyarakat sangat mengharapkan agar semua jalan bisa segera diberi lapisan perkerasan sirtu secara menyeluruh untuk mempermudah akses kegiatan masyarakat transmigran. Agar tidak terjadi kesenjangan sosial antara penduduk lokal dengan masyarakat transmigran, diharapkan pemerintah juga memperbaiki kondisi jalan di pedesaan lokal, karena akses kegiatan masyarakat transmigran selalu melalui jalan desa, karena merupakan jalur akses utama menuju ke kota. Hal ini dapat dilihat pada "Gambar. 4". 


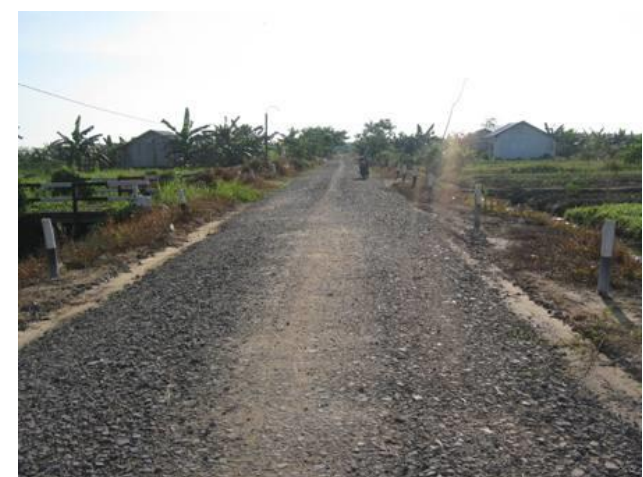

Lapisan Jalan dengan sirtu

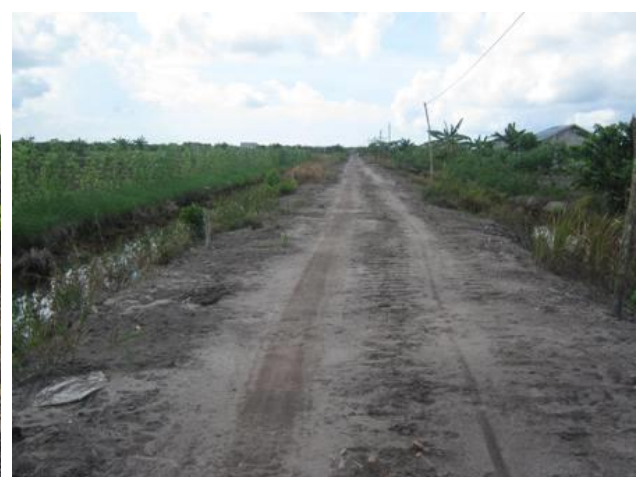

Lapisan jalan tanpa sirtu

Gambar. 4 Kondisi Jalan yang rusak di Kumai Seberang

\section{b. Saluran Drainase}

Pada saluran drainase jalan yang berada dikedua sisi jalan kondisinya cukup baik, akan tetapi sering terjadi pendangkalan akibat terjadinya erosi dari tebing saluran terutama pada saat hujan turun sehingga aliran air pada saluran drainase menjadi terhambat. Saluran drainase ini selain digunakan untuk menerima aliran air dari jalan, juga digunakan sebagai saluran irigasi untuk areal persawahan dan perkebunan. Hal ini dapat dilihat pada "Gambar. 5".

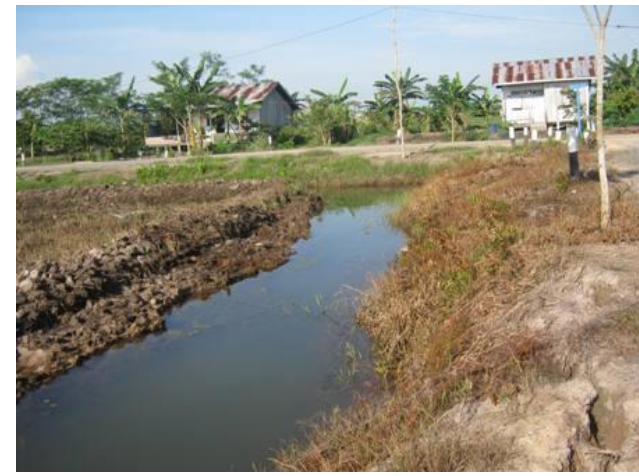

Penyempitan saluran

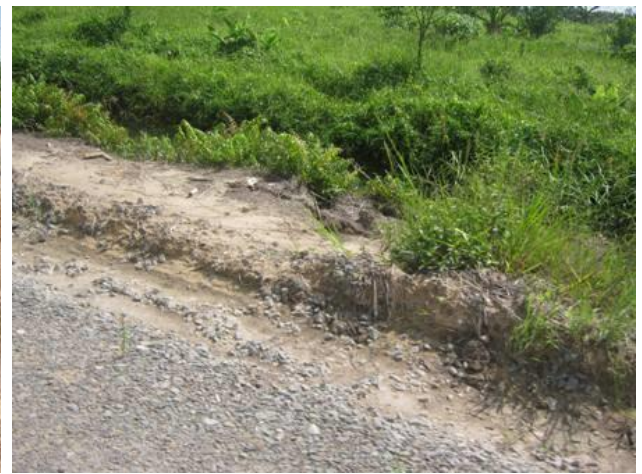

Timbunan pada pinggir jalan

Gambar. 5 Saluran drainase jalan yang tersumbat

c. Dinding penahan tanah

Pada saluran drainase tidak tedapat dinding penahan tanah, sehingga permasalahan yang sering dihadapi adalah erosi pada tebing saluran yang membuat saluran menjadi dangkal dan membuat aliran tersumbat. Masyarakat telah melakukan pembersihan endapan pada saluran secara gotong royong dan berkala, akan tetapi penempatan endapan lumpur yang diletakkan dipinggiran jalan membuat air pada jalan tidak dapat mengalir langsung ke saluran dikarenakan terhalang oleh timbunan endapan. Bila hal ini dibiarkan secara terus menerus akan menyebabkan kepadatan tanah jalan semakin berkurang dan secara berangsur-angsur jalan akan mejadi rusak seperti jalan berlubang, bergelombang, dan lain-lain. Hal ini dapat dilihat pada "Gambar. 6".

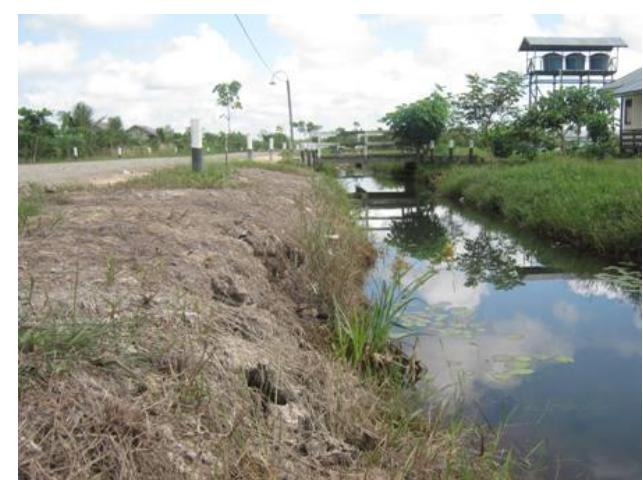

Erosi pada tebing

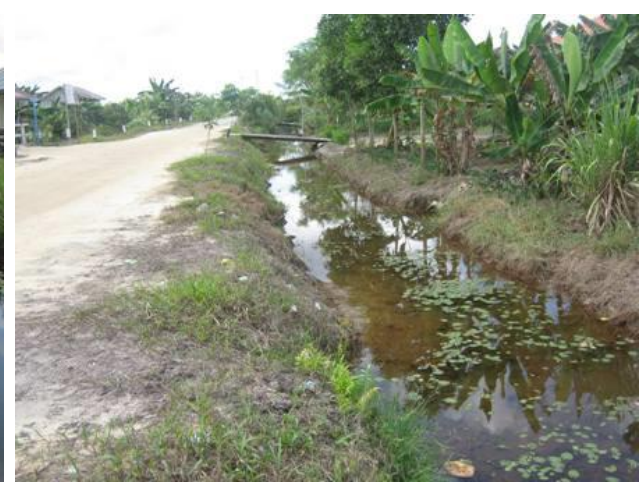

Pendangkalan saluran 


\section{Gambar. 6 Kondisi Saluran drainase}

\section{d. Jembatan}

Jembatan yang digunakan merupakan jembatan kayu. Kondisi jembatan masih dalam kondisi yang baik. Bagian tebing saluran di dekat abutmen jembatan sudah mulai terjadi erosi dan terdapat sedimen. Hal ini dapat dilihat pada "Gambar. 7".

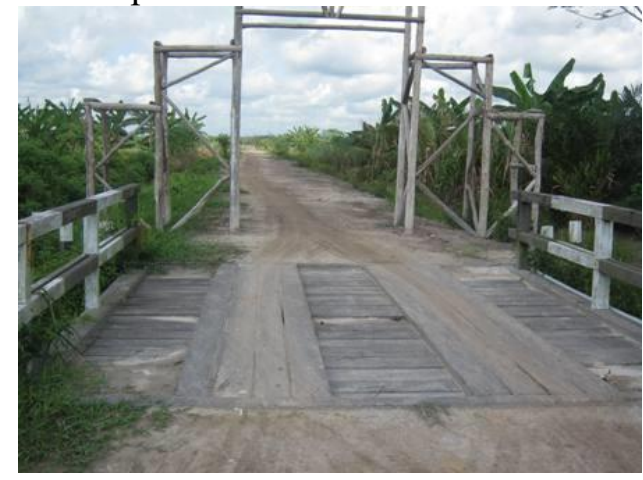

Jembatan Kayu

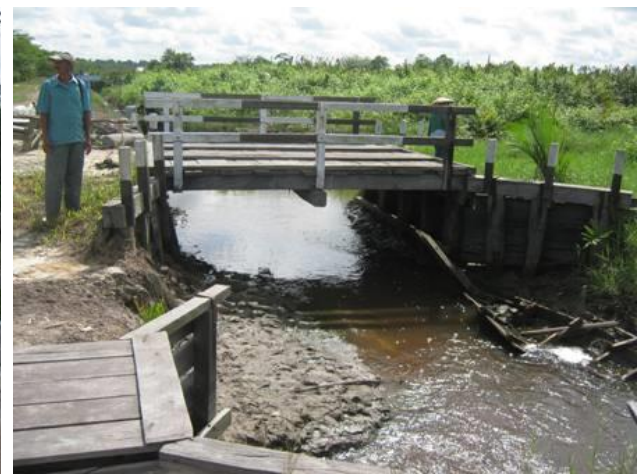

Endapan pada area jembatan

Gambar. 7 Kondisi Jembatan Kayu

e. Pintu Air

Pintu air merupakan pengatur aliran air yang mengalir ke saluran air yang melewati areal transmigrasi yang merupakan jaringan irigasi sementara untuk pengairan area persawahan dan perkebunan. Akan tetapi air yang mengalir belum optimal. Masyarakat mengharapkan agar dibangun lagi pintu-pintu air di beberapa tempat yang memungkinkan air mengalir pada areal yang kekurangan pasokan air. Hal ini dapat dilihat pada "Gambar. 8".

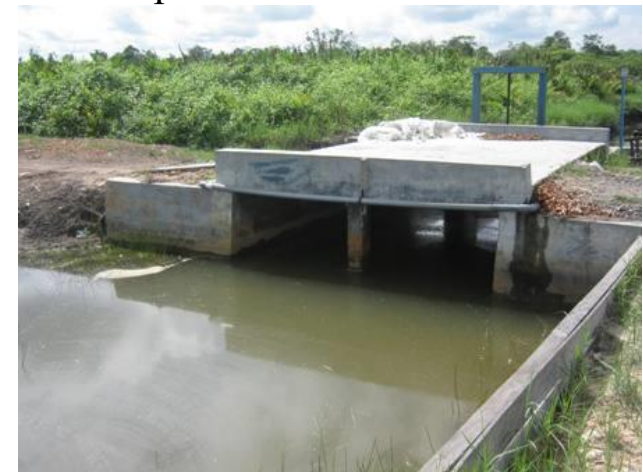

Pintu air dari beton

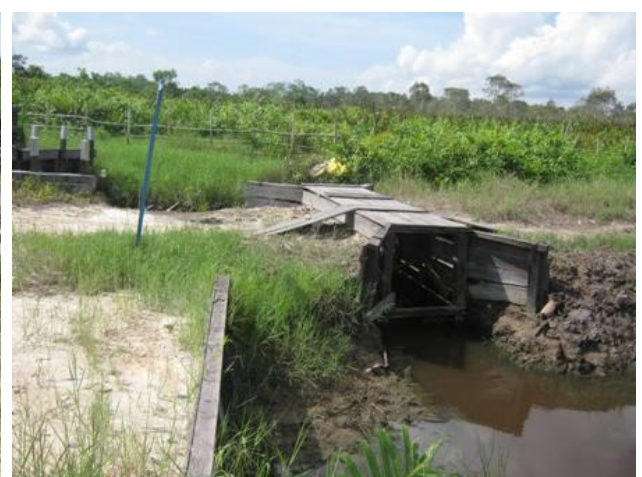

Pintu air dari kayu

Gambar. 8 Kondisi Pintu Air

f. Air Asin

Masyarakat kesulitan dalam mendapatkan air tawar, dikarenakan air yang berada pada areal persawahan dan perkebunan sudah bercampur dengan air asin. Masyarakat berharap dibangun kolam pengolah air asin menjadi air tawar, sehingga bisa digunakan untuk kegiatan irigasi dan rumah tangga.

\section{REKOMENDASI}

Solusi sederhana untuk penanganan masalah prasaranan jalan telah disampaikan pada saat sosialisasi dan pelatihan praktik di lapangan, serta telah dilampirkan di dalam modul pelatihan berupa banner dan buku. Contoh penangan sederhana untuk masalah prasarana jalan diantaranya:

1. Kondisi jalan di Kumai Seberang masih terlihat baik. Untuk menjaga agar jalan tetap berfungsi dalam jangka waktu lama, masyarakat harus melakukan pemeliharaan misalnya bila terjadi kerusakan kecil. Sebagai contoh masalah Jalan yang berlubang, becek dan bergelombang adalah dengan dipadatkan menggunakan stamper dari kayu, dan jalan yang belum mempunyai saluran drainase agar dibuat, serta dihindarkan menaruh timbunan tanah agar air bisa mengalir ke saluran 
dan tidak menggenang di jalan yang dapat membuat kepadatan jalan berkurang. Hal ini dapat dilihat pada "Gambar. 9".
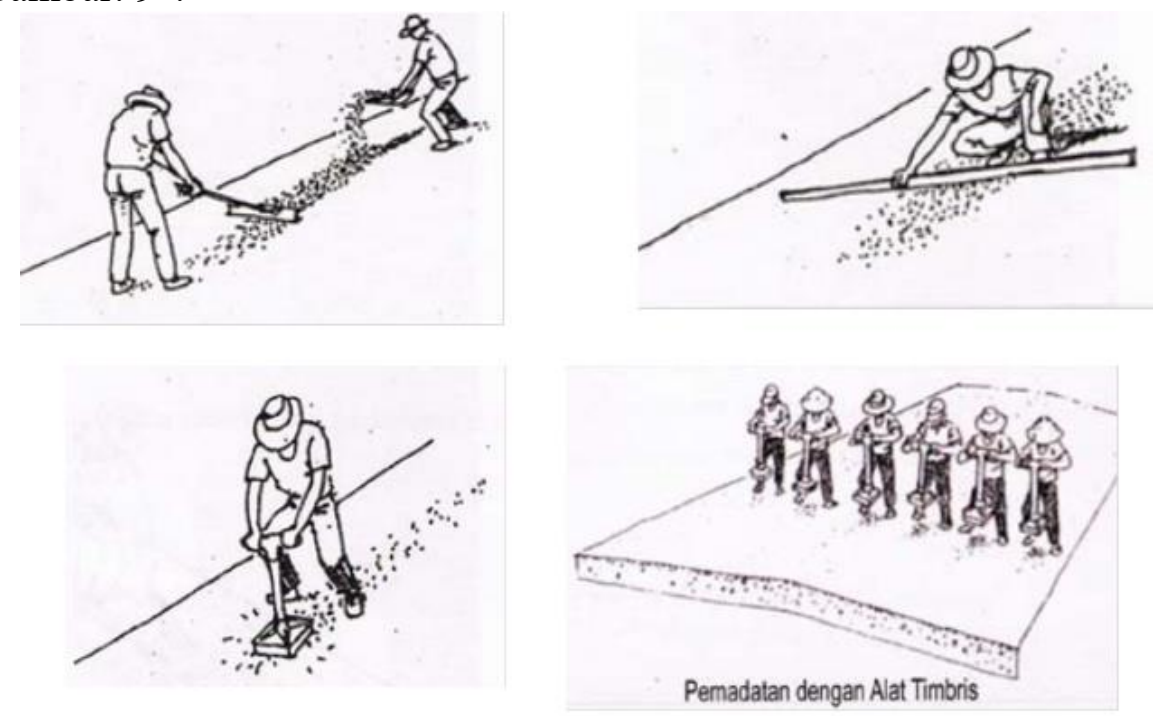

Sumber: google.com

Gambar. 9 Penambahan sirtu dan pemadatan menggunakan stamper kayu atau timbris

2. Masalah saluran drainase yang tersumbat dan terjadi pendangkalan adalah dengan memperbaiki kemiringan saluran dan selalu menggali endapan saluran secara berkala melalui kerjasama penduduk transmigran. Hal ini dapat dilihat pada "Gambar. 10".

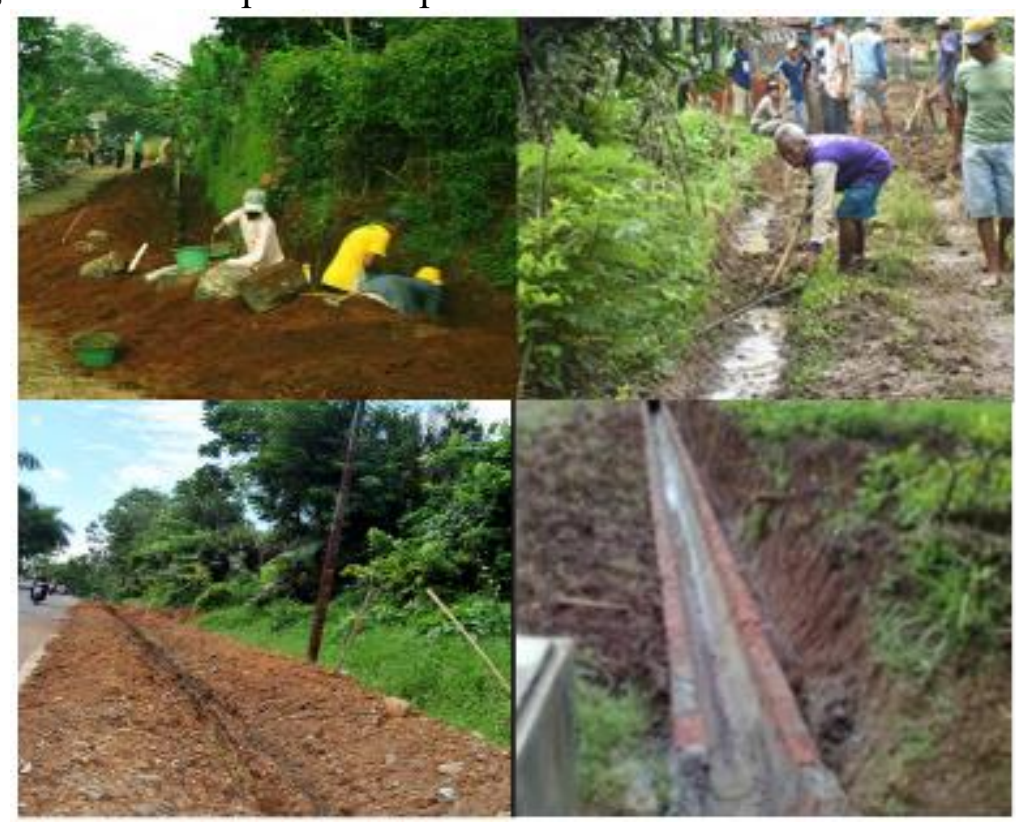

Sumber: google.com

Gambar. 10 Penggalian saluran drainase

3. Masalah dinding penahan tanah yang erosi adalah dengan memanfaatkan bahan yang tersedia ditempat, seperti memasang cerucuk dari kayu gelam, karung yang di isi pasir atau secara vegetatif dengan penanaman rumput vetiver atau rerumputan yang memiliki akar yang panjang menggunakan bantalan kayu. Hal ini dapat dilihat pada "Gambar. 11". 


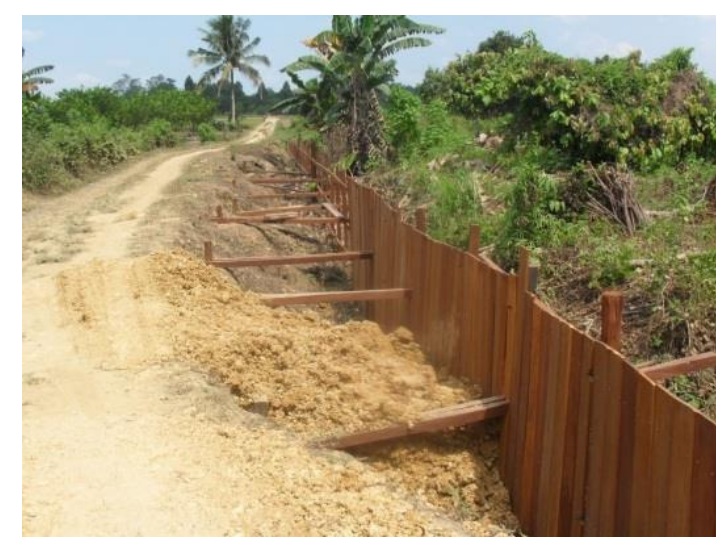

Dinding penahan tanah dari papan

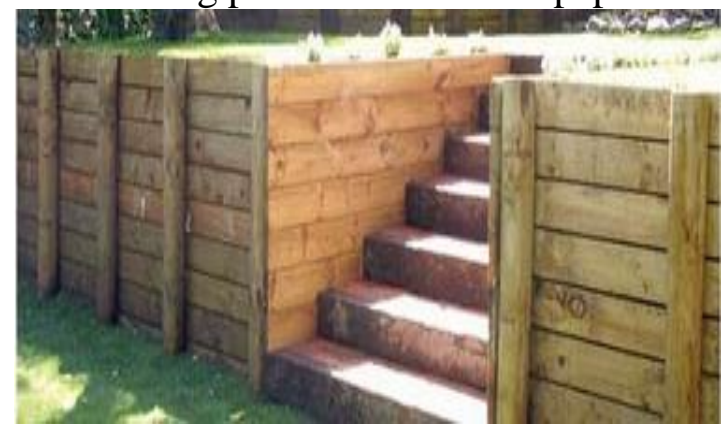

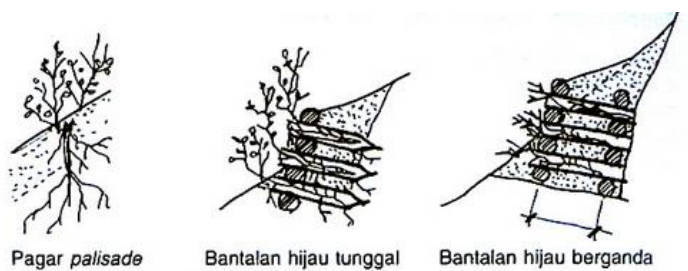

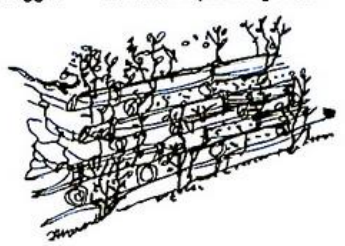

Isometri bantalan hijau yang selesai

Susunan beronjong sebaga tepi perairan yang ditanami

Perlakuan Vegetatif dengan bantalan kayu

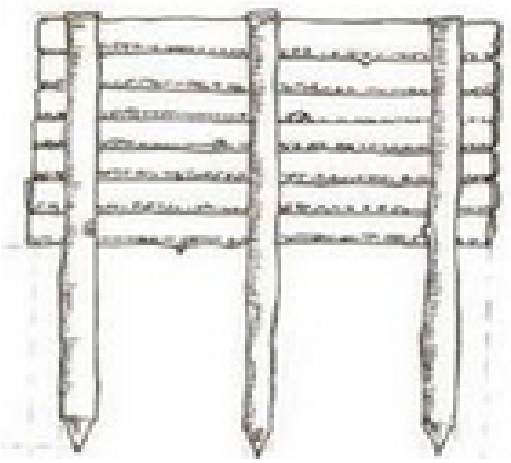

Penahan tanah dengan papan dan kayu gelam

Sumber: google.com

Gambar. 11 Contoh Jenis-jenis dinding penahan tanah

4. Pintu Air dan jembatan masih dalam kondisi yang baik sehingga harus dijaga supaya tetap berfungsi secara optimal sampai ada bantuan dari pemerintah untuk bantuan penambahan pembangunan pintu air khususnya daerah Kumai Seberang.

5. Untuk tebing saluran drainase ataupun yang berada di dekat abutmen jembatan bisa dipasang cerucuk kayu untuk mencegah erosi, penempatan galian tanah harus menjauhi saluran agar tidak terjadi erosi dan pendangkalan, seperti pada "Gambar. 12".

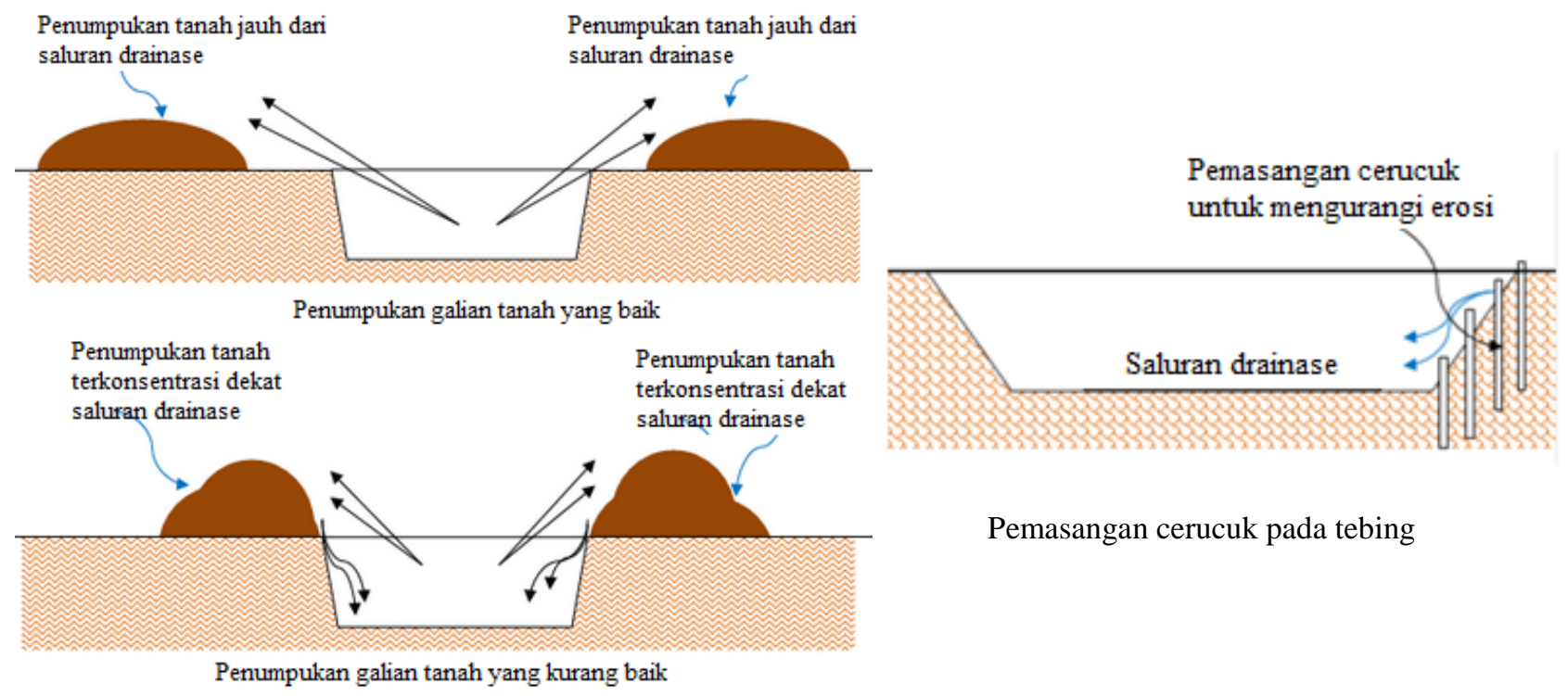

Sumber: google.com

Gambar. 12 penempatan galian dan pemasangan cerucuk pada tebing

6. Air asin akan dibahas lebih lanjut dengan instasi terkait agar bisa membantu dalam hal pengolahan air asin menjadi air tawar. 
7. Tebing saluran yang memungkinkan terjadinya erosi karena adanya arus yang deras bisa diatasi dengan memasang susunan cerucuk kayu sebagai pemecah arus setiap 10 meter atau dibuat seperti penangkap sedimen seperti pada "Gambar. 13"

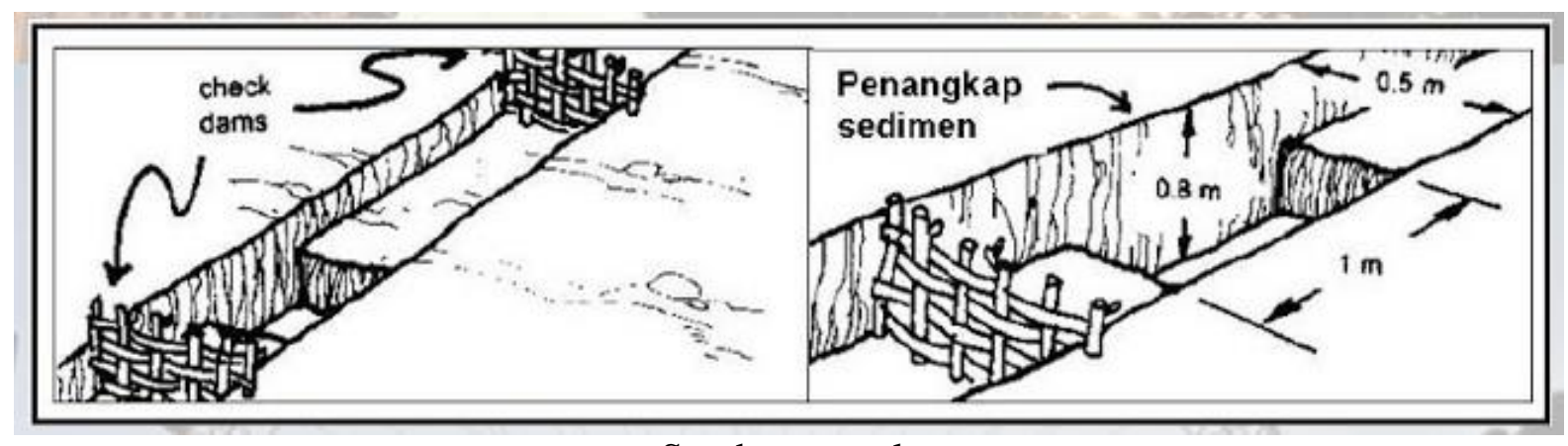

Sumber: google.com

Gambar. 13 Penangkap Sedimen

\section{KESIMPULAN}

Dari hasil observasi dan wawancara disimpulkan bahwa daerah Kumai Seberang memerlukan perbaikan dalam hal dinding penahan tanah untuk mengatasi erosi pada dinding saluran. Perlu ditambah pintu air untuk mengalirkan air ke areal persawahan dan perkebunan areal transmigrasi. Serta adanya bak penampung untuk mengolah air asin menjadi air tawar. Perlu adanya monitoring dan evaluasi secara berkala untuk pemeliharan sarana dan prasarana jalan dari pemerintah pusat dan daerah juga masyarakat setempat.

Penduduk Kumai Seberang dari segi kerjasama antar masyarakat sudah cukup baik dan beberapa penduduk ada yang sudah memahami sebagian pengetahuan tentang pengelolaan prasarana jalan, tetapi belum terarah secara optimal. Perlu dilakukan pembinaan kelembagaan secara intensif terhadap lembaga pemelihara prasarana jalan yang telah ada pada masyarakat transmigrasi.

\section{UCAPAN TERIMAKASIH}

Ucapan terimakasih kepada Kementerian Tenaga Kerja dan Transmigrasi dan PT. Tritis Bina Mandiri yang telah membiayai penelitian dengan topik Evaluasi sarana dan prasarana jalan transmigrasi di Kumai Seberang Kabupaten Waringin Barat Provinsi Kalimantan Tengah.

\section{REFERENSI}

1. Panduan Teknis Jalan Desa, 2008, “INFRASTRUKTUR DESA”, Awanda_stroom@yahoo.com, diakses Desember 2014.

2. Pedoman Umum Budidaya Pertanian di Lahan Pegunungan, 2011 "Identifikasi, perencanaan dan pengendalian lahan rawan longsor", Mahdi W , diakses Desember 2014.

3. PT.SIGMA TEKNIK MULTISTRUKTUR, 2013, "Bendungan" dapat diakses pada: http://sigmateknikmultistruktur.blogspot.com/

4. Wilkipedia, 2013, "Jembatan" dapat diakses pada: http://id.wikipedia.org/wiki/Jembatan

5. Bambang S, Muntohar. S. H., 2007, “Jembatan”, Yogyakarta : Beta Offset dapat di akses pada: http://www.galeripustaka.com/2014/05/jembatan-sederhana-kayu.html

6. www.depnakertrans.go.id

7. www.google.com

8. Undang-Undang Republik Indonesia Nomor 38 Tahun 2004 Tentang Jalan

9. Peraturan Menteri Pekerjaan Umum Republik Indonesia Nomor 13/PRT/M/2011 tentang Tata Cara Pemeliharaan dan Penilikan Jalan

10. Warsilan dan Noor A, 2015, Peranan Infrastruktur terhadap Pertumbuhan Ekonomi dan Implikasi pada Kebijakan Pembangunan di Kota Samarinda, MIMBAR, Vol. 31, No. 2 (Desember, 2015): 359-366 
11. Auzan AN dkk, 2017, Perencanaan Drainase Kawasan Pagarsih kota Bandung, JURNAL KARYA TEKNIK SIPIL, Volume 6, Nomor 4, Tahun 2017, Halaman 280 - 289 Online di: http://ejournal-s1.undip.ac.id/index.php/jkts

12. Wibisono AG, Noerhayati E, dan Rachmawati A, 2018, Studi Perencanaan Dinding Penahan Tanah pada Tebing Sungai Brantas di Area Kampus Universitas Muhammadiyah Malang (UMM) Kota MalangJurnal Rekayasa Sipil | Vol. 6 No. 1 Februari 2018 Jurnal Rekayasa Sipil | Vol. 6 No. 1 Februari 2018 